Article

\title{
Effects of a Heat Wave on Nocturnal Stomatal Conductance in Eucalyptus camaldulensis
}

\author{
Víctor Resco de Dios ${ }^{1,2, *(1)}$, Michael E. Loik ${ }^{3}$, Renee A. Smith ${ }^{4}$ and David T. Tissue 4 (1) \\ 1 School of Life Science and Engineering, Southwest University of Science and Technology, \\ Mianyang 621010, China \\ 2 Department of Crop and Forest Sciences and AGROTECNIO Center, Universitat de Lleida, 25198 Lleida \\ 3 Department of Environmental Studies, University of California, Santa Cruz, CA 95064, USA, Spain; \\ mloik@ucsc.edu \\ 4 Hawkesbury Institute for the Environment, Western Sydney University, Richmond NSW 2753, Australia; \\ R.Smith@westernsydney.edu.au (R.A.S.); D.Tissue@westernsydney.edu.au (D.T.T.) \\ * Correspondence: v.rescodedios@gmail.com; Tel.: +34-973-70-2532
}

Received: 5 March 2018; Accepted: 31 May 2018; Published: 3 June 2018

check for updates

\begin{abstract}
Nocturnal transpiration constitutes a significant yet poorly understood component of the global water cycle. Modeling nocturnal transpiration has been complicated by recent findings showing that stomata respond differently to environmental drivers over day- vs. night-time periods. Here, we propose that nocturnal stomatal conductance depends on antecedent daytime conditions. We tested this hypothesis across six genotypes of Eucalyptus camaldulensis Dehnh. growing under different $\mathrm{CO}_{2}$ concentrations (ambient vs. elevated) and exposed to contrasting temperatures (ambient vs. heat wave) for four days prior to the night of measurements, when all plants experienced ambient temperature conditions. We observed significant effects after the heat wave that led to $36 \%$ reductions in nocturnal stomatal conductance. The response was partly driven by changes in daytime stomatal behavior but additional factors may have come into play. We also observed significant differences in response to the heat wave across genotypes, likely driven by local adaptation to their climate of origin, but $\mathrm{CO}_{2}$ played no effect. Stomatal models may need to incorporate the role of antecedent effects to improve projections particularly after drastic changes in the environment such as heat waves.
\end{abstract}

Keywords: climate change; ecological memory; forests; genotype; gas exchange; legacy effects; nighttime processes; transpiration; water

\section{Introduction}

The opening of stomata during dark periods defies established conventions in both hydrology and plant physiology. Major assumptions in hydrometeorology include negligible nocturnal evapotranspiration [1], but sap flux studies record that, averaged across a range of species, nighttime transpiration amounts to $12 \%$ of daytime [2]. Including nocturnal transpiration into land surface models leads to reductions of up to $50 \%$ of the projected available soil moisture in semiarid environments [3]. Understanding the function of nocturnal water loss remains a conundrum because one of the organizing principles in plant physiology is that stomata operate optimally to minimize the rate of water lost per unit of assimilated carbon [4]. Consequently, stomata are theorized to remain closed overnight in $\mathrm{C} 3$ and $\mathrm{C} 4$ plants because there is no net photosynthetic $\mathrm{CO}_{2}$ assimilation at that time; however this contrasts with reality, where significant nocturnal stomatal opening across species seems to be the norm rather than the exception [5-7].

Understanding the drivers of stomatal function in the dark has proven more challenging than anticipated. This is partly because nighttime stomatal responses do not always follow the same pattern 
as daytime responses [8]. Some studies document that nocturnal stomatal conductance responds positively to elevated $\mathrm{CO}_{2}$ [9], which is opposite to the common diurnal response. Also, stomatal responses to vapor pressure deficit may be either neutral (i.e., no response) or positive, which again contradict the daytime pattern $[10,11]$.

One of the possible mechanisms explaining differential day/night stomatal regulation is the effect of antecedent conditions. For instance, Easlon and Richards [12] found that nocturnal stomatal conductance in Vicia faba L. decreased after days with reduced rates of carbon assimilation induced by low $\mathrm{CO}_{2}$ concentrations. They associated this response with a potentially lower availability of starch, a compound that can be converted to sugars that serve as an osmoticant necessary for stomatal regulation. However, subsequent studies observed that nocturnal stomatal conductance was constant after exposing canopies of bean and cotton to different levels of solar radiation, which indicated a limited potential for a day/night carry-over effect driven by daytime assimilation in those species [13].

Heat waves are an environmental factor which may impact subsequent nocturnal conductance. Important stresses during the day may modify leaf anatomical or physiological properties and exert carry-over effects beyond the duration of the stress event. For instance, Duarte et al. [14] observed reduced nocturnal stomatal conductance in the weeks following a series of heat waves in Pseudotsuga menziesii (Mirb.) Franco, and they attributed this response to changes in stomatal occlusion or greater epicuticular wax. When such changes occur, which affect stomatal behavior as a whole (that is, day- and night- time stomatal behavior), one may expect that daytime and nighttime nocturnal stomatal conductance will vary accordingly in a coordinated fashion. However, other stomatal responses to heat waves are also possible. Some studies hypothesize, for instance, that nocturnal stomatal conductance favors stem water recharge [6]. If true, the high daytime transpiration that occurs during a heat wave, which depletes stem water capacitance, should lead to increased nocturnal stomatal conductance for xylem refilling. Alternatively, if assimilation is reduced during the heat wave [12], we should observe a reduction of nocturnal stomatal conductance, according to the hypothesis that daytime assimilation controls nighttime stomatal conductance.

The potential for antecedent daytime conditions affecting water fluxes in the following night, and responses during heat waves, are not well understood. To the best of our knowledge, the study with P. menziesii, a conifer [14], is the only study to measure nocturnal stomatal conductance after heat waves. However, elucidating the mechanisms explaining stomatal regulation in the dark is key towards improving stomatal models, which often show mixed results over nocturnal periods $[14,15]$. Furthermore, the increasing frequency of heat waves is more consistently projected to occur in the future [16]. Understanding the responses of nocturnal stomatal conductance to heat waves and potential carry-over effects thus remains an important research need.

Here, we sought to disentangle the possible effects of antecedent daytime conditions on nocturnal stomatal conductance by examining the response on the night immediately following a heat-wave event for genotypes of Eucalyptus camaldulensis grown in ambient and elevated $\mathrm{CO}_{2}$ concentrations. More specifically, we addressed the following questions: (1) Does nocturnal conductance change in response to heat waves, even after the heat wave ends? (2) Is the response of nocturnal conductance to heat waves affected by different growth $\mathrm{CO}_{2}$ concentrations? (3) How much does genotypic variability contribute to the response of nocturnal conductance to heat waves and $\mathrm{CO}_{2}$ ?

To address the first question, we hypothesized that antecedent heat-wave conditions would affect nocturnal stomatal conductance. To understand how that impact would occur, we wanted to test three mutually compatible hypotheses: (i) stress from the heat wave affects overall stomatal behavior, including nighttime conductance, and consequently day and night conductance would be correlated; (ii) heat-wave-induced changes in photosynthetic carbon assimilation correlate positively with nocturnal stomatal conductance (potentially via carbohydrate feedbacks); (iii) heat-wave-induced changes in daytime whole-plant transpiration correlate positively with nocturnal stomatal conductance (potentially through stem recharge). To address the second question, we hypothesized that heat-wave-induced effects would depend on $\mathrm{CO}_{2}$ concentrations because elevated $\mathrm{CO}_{2}$ often increases 
photosynthesis in the absence of nutrient limitations, and this could counter the negative effects of the heat wave. To address the third question, we used different genotypes because we found genetic control of nocturnal stomatal conductance in this species [17] and, consequently, we expected differences based on the climate of origin. Furthermore, previous studies have proposed examining responses across genotypes to increase the reproducibility of the results [18].

\section{Materials and Methods}

\subsection{Plants and Growing Conditions}

Seedlings from six different genotypes of E. camaldulensis subsp. camaldulensis were prepared from clonal hedges by the Commonwealth Scientific and Industrial Research Organization (see Table A1 for full details on provenances). The hedges were half-sib seedlings originating from provenances representing different geographic and climatic origins. After reaching an average height of $24.6 \mathrm{~cm}$ $( \pm 0.97 ; \mathrm{SE})$ and a basal diameter of $1.86 \mathrm{~mm}( \pm 0.07)$, genotypes were transplanted into $6.9 \mathrm{~L}$ cylindrical pots and grown at the naturally lit (with $20 \%$ reduction of incident radiation) glasshouse facilities of Western Sydney University in Richmond, New South Wales, in southeastern Australia. No differences in height and diameter occurred between genotypes at experiment initiation $(P>0.05$, ANOVA).

Each pot contained $7.5 \mathrm{~kg}$ of coarse textured soil (supplied by Australian Native Landscape, Richmond, NSW, Australia), with a pH of 6.5. To ensure that no nutrient limitations occurred, the plants were fertilized every fortnight with a commercial liquid fertilizer $\left(500 \mathrm{~mL}\right.$ Aquasol at $1.6 \mathrm{~g} \mathrm{~L}^{-1} ; 23 \% \mathrm{~N}$, $4 \% \mathrm{P}, 18 \% \mathrm{~K}, 0.05 \% \mathrm{Zn}, 0.06 \% \mathrm{Cu}, 0.013 \% \mathrm{Mo}, 0.15 \% \mathrm{Mn}, 0.06 \% \mathrm{Fe}, 0.011 \% \mathrm{~B}$; Yates Australia, Padstow, NSW, Australia). Plants were grown in ambient $(400 \mathrm{ppm})$ or elevated $(640 \mathrm{ppm}) \mathrm{CO}_{2}$ concentrations and were randomly assigned to one of two glasshouse bays per $\mathrm{CO}_{2}$ treatment within a randomized block design ( $n=3-6)$. Pots were rotated between (monthly) and within (weekly) glasshouse bays to further reduce potential glasshouse bay effects on plant performance. Air temperatures $\left(25: 17^{\circ} \mathrm{C}\right.$, average day:night) and relative humidity (45\%:60\%) were representative of average summer values in Richmond. The pots were daily watered to field capacity (until water drained from the bottom of the pot) and, consequently, soil moisture variation did not affect our results.

The heat wave was imposed in half of the plants after three months of growth, and air temperatures in the glasshouse were increased by $10^{\circ} \mathrm{C}$ (day and night) for four days. We estimated the change in daytime relative humidity during the heat wave from the ratio of actual vapor pressure under ambient conditions divided by the saturation pressure during the heat wave [19]. Consequently, relative humidity during the heat wave was estimated at $25 \%$. Vapour pressure deficit thus increased from $1.75 \mathrm{kPa}$ during normal conditions to $4.23 \mathrm{kPa}$ during the heat wave. At dusk of the fourth day/night transition, air temperatures were returned to pre-heat-wave conditions. Daytime measurements were collected on the fourth day of the heat wave and nighttime measurements on the night immediately following that day, when air temperatures were already back to normal. In other words, daytime measurements were collected with half of the plants experiencing a heat wave (and the other half not experiencing a heat wave), but nighttime measurements were performed immediately after the heat wave under ambient pre-heat-wave conditions and, consequently, all plants experienced the same environment. Further details on glasshouse design and set-up are given by $[17,20]$.

\subsection{Measurements and Statistical Analyses}

Leaf gas exchange was measured with four cross-calibrated portable photosynthesis systems (LI-6400XT, Li-Cor Inc., Lincoln, NE, USA). Cross-calibration here means the systems had $\mathrm{H}_{2} \mathrm{O}_{\mathrm{v}}$ and $\mathrm{CO}_{2}$ removed to set the zero and ambient gains on the infrared gas analyzers simultaneously, side-by-side, under the same physical conditions, and using the same lots of soda lime and Drierite. Nocturnal gas exchange was measured at 3:45 a.m. (predawn). Conditions inside the LI-6400XT cuvettes were set to match the growth conditions previously described. To test whether nighttime stomatal conductance $\left(g_{\mathrm{n}}\right)$ followed daytime stomatal conductance $\left(g_{\mathrm{d}}\right)$, we measured $g_{\mathrm{n}}$ and $g_{\mathrm{d}}$. 
To test whether net assimilation $\left(A_{\text {net }}\right)$ affects $g_{\mathrm{n}}$, we also measured $A_{\text {net }}$. To test whether larger diurnal transpiration favors larger $g_{\mathrm{n}}$, we multiplied leaf level transpiration by total leaf area, rendering total plant transpiration $\left(E_{\mathrm{p}}\right)$ assuming a "big leaf" model structure. It is well known that big leaf scaling approaches are fairly limited, especially within complex canopies, given that leaf-gas exchange is heterogeneous within canopies and varies as a function of factors such as leaf position or age [21], and this variation could also be under genetic control. These problems would have been minimized within our design because the plants were 3-months old and little time had elapsed for complexity in the canopy structure to be developed. Total plant leaf area was determined during plant harvest during the week following measurements using a leaf area meter (LI-3100C, Li-Cor Inc., Lincoln, NE, USA).

We first examined statistical patterns in $g_{\mathrm{n}}, g_{\mathrm{d}}, A_{\text {net }}$, and $E_{\mathrm{p}}$ during the treatments with linear mixed models that included sampling time, $\mathrm{CO}_{2}$ concentrations, genotype, and their interactions as fixed variables, and with glasshouse bay nested within heat-wave treatment as random variables. We then correlated $g_{\mathrm{n}}$ with $g_{\mathrm{d}}, A_{\text {net }}$, and $E_{\mathrm{p}}$ to infer the potential for causal relationships among variables. These analyses were performed after examining whether the data conformed to assumptions of homoscedasticity and normality. All analyses were performed in the R software environment using base packages and lme4 [22].

\section{Results}

We observed significant differences in $g_{\mathrm{n}}$ as a function of whether or not plants had been exposed to a heat wave on the previous days, indicating the existence of carry-over effects (Table 1). The main effect was a significant decline in $g_{n}$ after the heat wave of $36.1 \%$, but responses varied across genotypes and $g_{\mathrm{n}}$ increased in one genotype (Figure 1). There were no effects of $\mathrm{CO}_{2}$ on $g_{\mathrm{n}}$.

Table 1. Results of linear mixed models on the effects of $\mathrm{CO}_{2}$, genotype, heat wave, and their interactions on nocturnal stomatal conductance $\left(g_{\mathrm{n}}\right)$, daytime stomatal conductance $\left(g_{\mathrm{d}}\right)$, leaf assimilation rates $\left(A_{\text {net }}\right)$, and whole plant transpiration $\left(E_{\mathrm{p}}\right)$, with glasshouse bay nested within $\mathrm{CO}_{2}$ concentration as random variables. $P$-values reflect the results of Wald tests on linear mixed model that included glasshouse bay nested within heat-wave treatment as random variables. Significant $(P<0.05)$ values are in bold text.

\begin{tabular}{ccccccccc}
\hline & \multicolumn{2}{c}{$g_{\mathbf{n}}$} & \multicolumn{2}{c}{$g_{\mathbf{d}}$} & \multicolumn{2}{c}{$A_{\text {net }}$} & \multicolumn{2}{c}{$E_{\mathbf{p}}$} \\
\hline & $\chi^{\mathbf{2}}$ & $\boldsymbol{P}$ & $\chi^{\mathbf{2}}$ & $\boldsymbol{P}$ & $\chi^{\mathbf{2}}$ & $\boldsymbol{P}$ & $\chi^{\mathbf{2}}$ & $\boldsymbol{P}$ \\
\hline $\mathrm{CO}_{2}$ & 0.001 & 0.99 & 0.09 & 0.75 & 27.42 & $<\mathbf{0 . 0 0 1}$ & 1.560 & 0.21 \\
Genotype & 41.01 & $<\mathbf{0 . 0 0 1}$ & 19.83 & $\mathbf{0 . 0 0 3}$ & 17.92 & $\mathbf{0 . 0 0 6}$ & 30.72 & $<\mathbf{0 . 0 0 1}$ \\
Heat wave & 11.85 & $<\mathbf{0 . 0 0 1}$ & 1.66 & 0.20 & 6.23 & $\mathbf{0 . 0 1}$ & 116.88 & $<\mathbf{0 . 0 0 1}$ \\
$\mathrm{C} \times \mathrm{G}$ & 8.67 & 0.12 & 7.68 & 0.26 & 4.99 & 0.54 & 4.33 & 0.50 \\
$\mathrm{C} \times \mathrm{H}$ & 0.07 & 0.79 & 13.45 & $<\mathbf{0 . 0 0 1}$ & 17.02 & $<\mathbf{0 . 0 0 1}$ & 16.97 & $<\mathbf{0 . 0 0 1}$ \\
$\mathrm{G} \times \mathrm{H}$ & 28.63 & $<\mathbf{0 . 0 0 1}$ & 6.45 & 0.26 & 6.04 & 0.30 & 10.41 & 0.06 \\
$\mathrm{C} \times \mathrm{G} \times \mathrm{H}$ & 6.99 & 0.22 & 4.63 & 0.46 & 2.39 & 0.79 & 5.44 & 0.56 \\
\hline
\end{tabular}



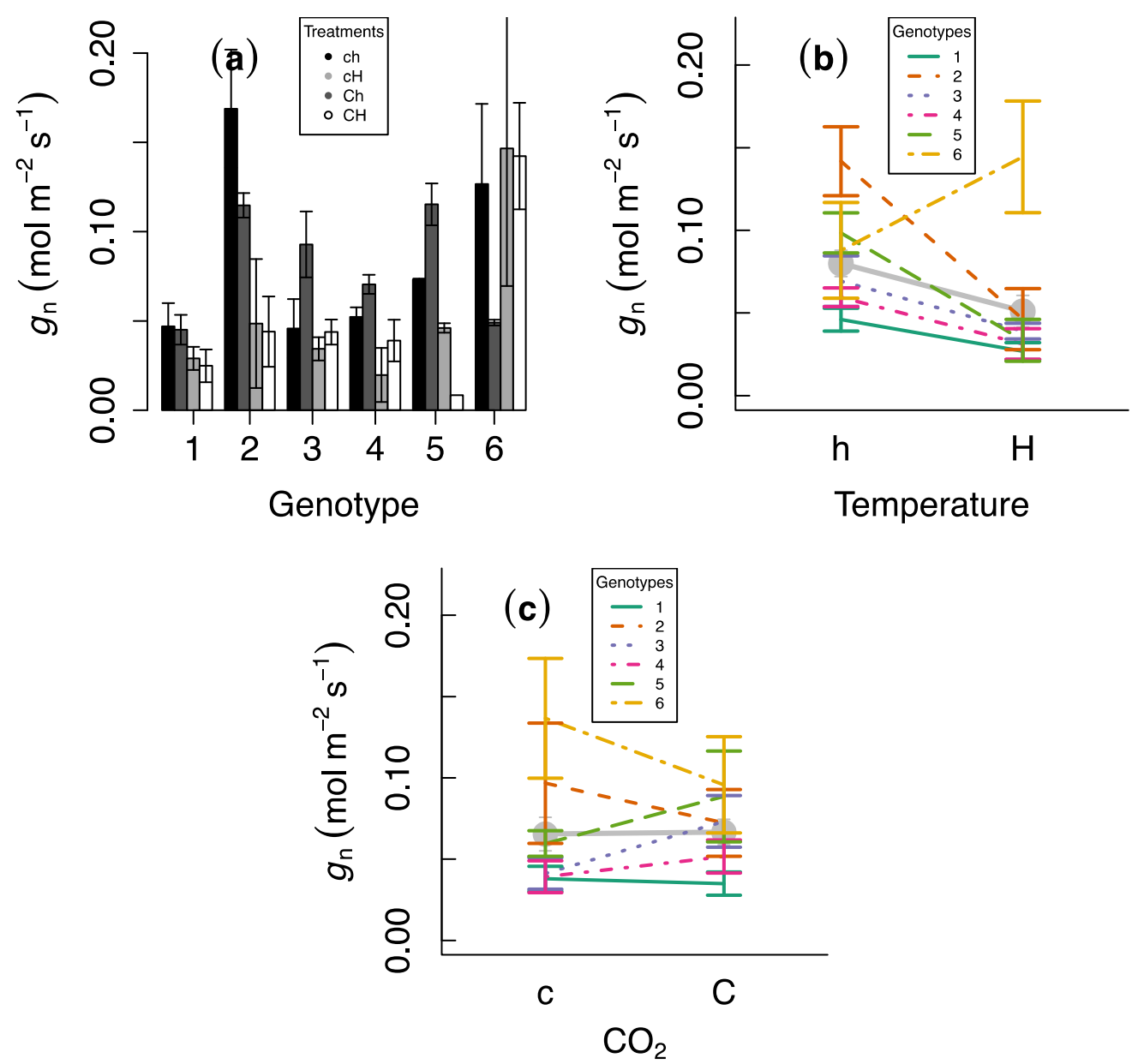

Figure 1. Experimental responses of nocturnal stomatal conductance. (a) Variation across genotypes as a function of heat-wave exposure and $\mathrm{CO}_{2}$ concentrations. (b) Reaction norms of heat-wave responses across genotypes. (c) Reaction norms of $\mathrm{CO}_{2}$ responses across genotypes. Grey in $(\mathbf{b}, \mathbf{c})$ indicates average values for all genotypes and the other colors indicate individual genotypes. $h, H, c$ and $C$ indicate no heat-wave exposure, heat-wave exposure, ambient $\mathrm{CO}_{2}$, and elevated $\mathrm{CO}_{2}$, respectively. Error bars indicate standard errors.

The response of daytime stomatal conductance and $\mathrm{CO}_{2}$ assimilation was also affected by the experimental treatments, although the effects were different for each of the traits (Table 1). $g_{d}$ varied significantly across genotypes (Figure 2a) and there was a significant $\mathrm{CO}_{2} \times$ heat-wave interaction such that, during the heat wave, $g_{\mathrm{d}}$ was higher in plants under elevated $\mathrm{CO}_{2}$ but lower under ambient $\mathrm{CO}_{2}$ (Figure $2 \mathrm{~b}$ ). $A_{\text {net }}$ also varied significantly across genotypes (Figure 2c), and although there was also a $\mathrm{CO}_{2} \times$ heat-wave interaction, in this case, there were no significant differences as a function of heat-wave exposure under ambient $\mathrm{CO}_{2}$, whereas there was a photosynthetic stimulation during the heat wave under elevated $\mathrm{CO}_{2}$ (Figure 2d). We also observed significant differences in $E_{\mathrm{p}}$ across genotypes (Figure 2e) and there was also a significant $\mathrm{CO}_{2} \times$ heat-wave interaction. $E_{\mathrm{p}}$ was always higher during the heat wave, but $E_{\mathrm{p}}$ increased with elevated $\mathrm{CO}_{2}$ during the heat wave and it decreased with elevated $\mathrm{CO}_{2}$ under ambient temperature. $E_{\mathrm{p}}$ will be affected by transpiration rate and also by leaf area. Although different genotypes showed differences in leaf area and $\mathrm{CO}_{2}$ increased leaf area, there were no differences in leaf area as a function of heat wave exposure, as expected (Figure A1).

To understand the possible mechanisms explaining the pattern in $g_{\mathrm{n}}$, we correlated this parameter against $g_{\mathrm{d}}, A_{\text {net }}$, and $E_{\mathrm{p}}$ and only observed a significant and positive correlation between $g_{\mathrm{n}}$ and $g_{\mathrm{d}}$ $(P=0.0047$, Figure 3$)$, although the regression had limited explanatory power $\left(R^{2}=0.13\right)$. 

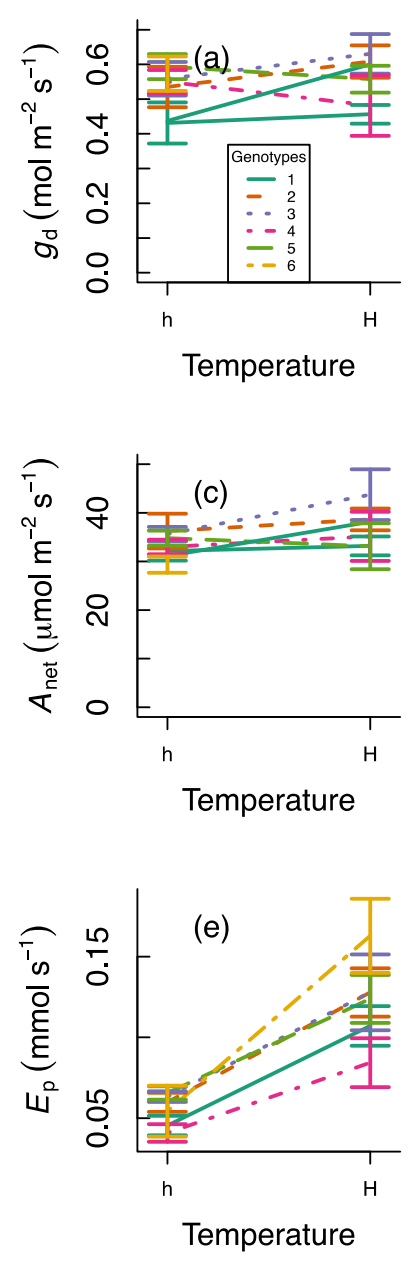
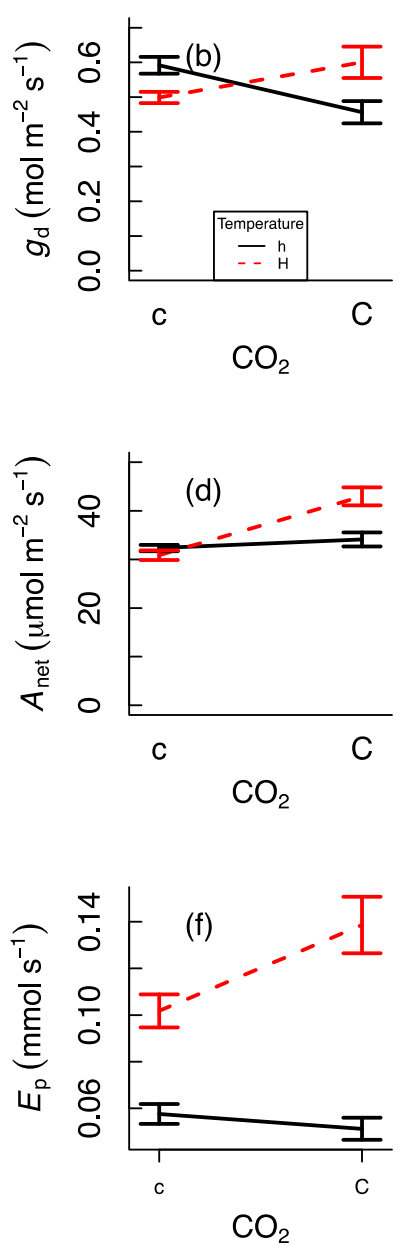

Figure 2. Experimental responses of daytime stomatal conductance $\left(g_{d} ; \mathbf{a}, \mathbf{b}\right)$, net photosynthesis $\left(A_{\text {net; }}\right.$; $\mathbf{c}, \mathbf{d})$, and whole plant transpiration $\left(E_{\mathrm{p}} ; \mathbf{e}, \mathbf{f}\right)$ in response to no heat-wave exposure $(\mathrm{h})$, heat-wave exposure $(\mathrm{H})$, ambient $\mathrm{CO}_{2}(\mathrm{c})$, and elevated $\mathrm{CO}_{2}(\mathrm{C})$. Data are presented as reaction norms for six genotypes as a function of temperature (figures $\mathbf{a}, \mathbf{c}, \mathbf{e}$ ) and as reaction norms for temperature as a function of $\mathrm{CO}_{2}$ treatment (figures $\mathbf{b}, \mathbf{d}, \mathbf{f}$ ). Error bars indicate standard errors.
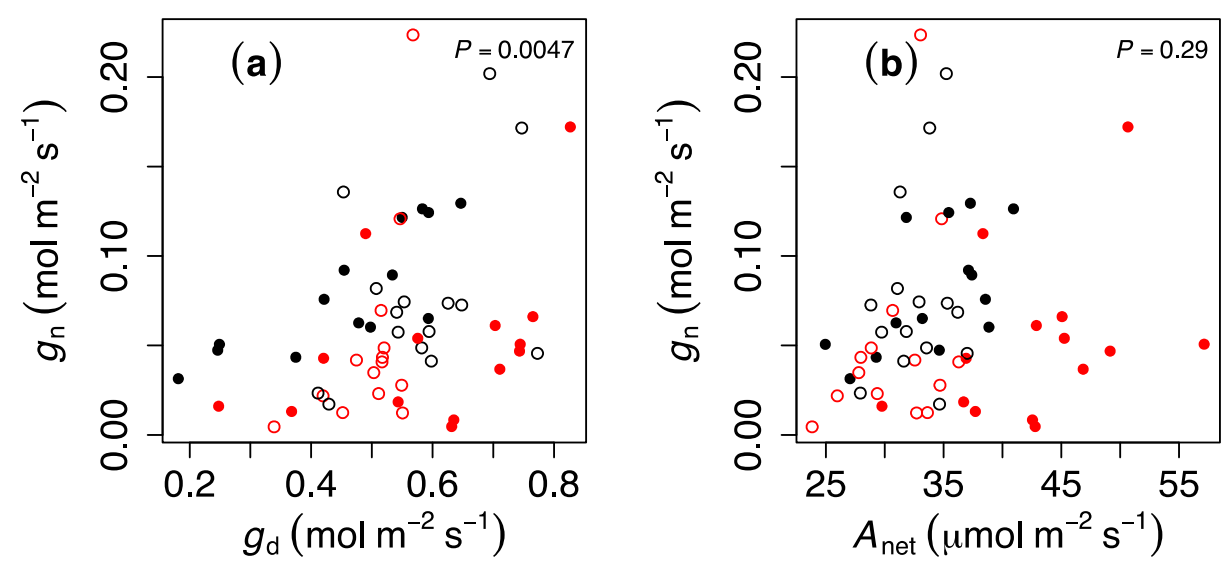

Figure 3. Cont. 


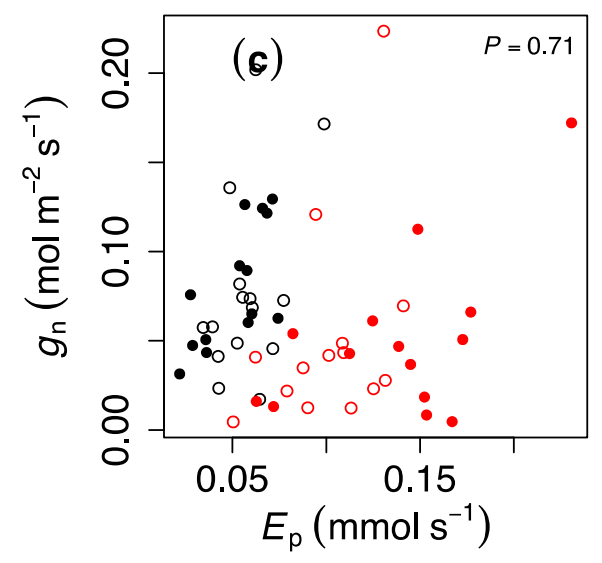

Figure 3. Relationship between nocturnal stomatal conductance $\left(g_{\mathrm{n}}\right)$ and (a) daytime stomatal conductance $\left(g_{\mathrm{d}},\right),(\mathbf{b})$ net assimilation $\left(A_{\text {net }}\right)$, and $(\mathbf{c})$ whole plant transpiration $\left(E_{\mathrm{p}}\right)$. Black and red values indicate ambient temperature and heat wave, respectively, and open and closed symbols indicate ambient and elevated $\mathrm{CO}_{2}$ concentrations, respectively. $P$-values indicate the result of least-squares fitting. Each value represents a single genotype.

\section{Discussion}

We observed that antecedent daytime environmental conditions affect nocturnal stomatal conductance. The response was largely consistent (but not uniform) across genotypes, but none of the previously hypothesized processes fully explain the response.

Current stomatal models assume nearly immediate response to environmental conditions and that antecedent environmental conditions exert no effect on stomata [23]. However, Resco de Dios et al. [24] proposed that stomatal models should consider circadian effects because the clock controlled up to $70 \%$ of the diurnal pattern in stomatal conductance in two crop species. They argued that circadian regulation acts as a "memory" such that the plant may anticipate predictable environmental changes (e.g., dawn/dusk transitions) based upon information from past environmental conditions. Here, we demonstrate that antecedent effects are an additional process whereby past environmental conditions may affect nocturnal stomatal behavior.

A crucial challenge will be to identify which daytime environmental processes affect the nocturnal stomatal response. Here, we observed that $\mathrm{CO}_{2}$ effects, which significantly affected $g_{\mathrm{d}}, A_{\text {net }}$, and $E_{\mathrm{p}}$, did not have an impact on $g_{\mathrm{n}}$. We had previously identified the lack of an effect of elevated $\mathrm{CO}_{2}$ on $g_{\mathrm{n}}$ in this species [19], but we did expect that $g_{\mathrm{n}}$ would be affected by a $\mathrm{CO}_{2} \times$ heat-wave interaction because elevated $\mathrm{CO}_{2}$ significantly affected $g_{\mathrm{d}}$ responses.

We increased the temperature by $10^{\circ} \mathrm{C}$ over four days, which also increased the vapor pressure deficit, and observed significant reductions in $g_{n}$, averaged across genotypes, of $36 \%$ in the night after the heat wave (grey values in Figure 1b). This may be the first report of heat waves impacting $g_{\mathrm{n}}$ in an angiosperm. Previous work on $g_{n}$ examined heat-wave responses in a conifer species [14] and in hardwoods, but only sap flux responses were assessed [25].

Why did we observe that $g_{\mathrm{n}}$ was affected by antecedent heat waves but not by antecedent $\mathrm{CO}_{2}$ ? While further studies will be necessary to fully decipher this question, here we can offer some hypotheses. First, it should be noted that $\mathrm{CO}_{2}$ treatments were applied for the entire growing period, but the heat wave was imposed for only a few days and, consequently, the effect of these two environmental drivers is not fully comparable. Additionally, it could be argued that only drastically different environmental conditions may lead to carry-over effects. For instance, Easlon and Richards [12] observed that low daytime $\mathrm{CO}_{2}$ decreased $g_{n}$, but in their experimental design, they completely scrubbed $\mathrm{CO}_{2}$ from the air to $0 \mathrm{ppm}$ and, consequently, leaves may have been carbon starved when the night arrived. Others have similarly found that sucrose limitations explain variation in $g_{\mathrm{n}}$ in some temperate trees [26]. Our $\mathrm{CO}_{2}$ treatments (400 and $640 \mathrm{ppm}$ ) would not have led to 
such dramatic effects and carbohydrate concentrations were generally not limiting [27]. By contrast, during our heat wave, we raised the temperatures by $10^{\circ} \mathrm{C}$, and this had important consequences for plant transpiration.

Duarte et al. [14] hypothesized (but did not measure) that changes in anatomical properties, such as stomatal occlusion or changes in epicuticular wax, could have occurred during the heat wave, and that led to carry-over effects in Douglas fir. A corollary from this hypothesis is that daytime and nighttime conductance should be proportionally reduced because physical changes in occlusion, for instance, would similarly affect daytime and nighttime conductance. Consistent with this hypothesis, we observed a significant correlation between $g_{\mathrm{n}}$ and $g_{\mathrm{d}}$ (Figure 3a), but it only explained $13 \%$ of the variation in $g_{n}$, indicating that additional processes must be playing a role. However, a role for cuticular conductance here remains dubious since previous studies in Eucalypts report values of $0.003 \mathrm{~mol} \mathrm{~m}^{-2} \mathrm{~s}^{-1}$ [28], a value that is between 1 and 2 orders of magnitude smaller than the values of $g_{\mathrm{n}}$ reported here.

Our findings are also not consistent with the notion that heat waves exert carry-over effects due to increased xylem hydraulic recharge because there was no correlation between $g_{\mathrm{n}}$ and $E_{\mathrm{p}}$. We note, however, that this hypothesis is not exempt from criticism. In fact, it could also be argued that stem recharge would actually benefit from stomatal closure (not opening), as transpiration lowers the leaf-level water potential and, consequently, breaks the equilibrium with soil water potential that favors recharge [29].

Previous studies had documented genetic variability in $g_{n}$ in a range of species [19,30,31], but we demonstrate, for the first time, genetic variability in $g_{n}$ responses to heat waves (Figure 1b). Eucalyptus camaldulensis is a riparian species, with deep roots in mature trees, that does not usually suffer from drought in its native range. Variability in $g_{n}$ may thus be advantageous because genotypes with higher $g_{n}$ may assimilate more $C$ in the morning [19], with minimal danger of soil water scarcity in deep-rooted trees in riparian environments.

Genetic variability in the response to heat waves could be related to the climate of origin [20]. We did not perform detailed analyses based on climate of origin because we only had one genotype from each location. However, we note that the genotype that responded positively in $g_{\mathrm{n}}$ to the heat wave (Genotype 6) originated from one of the locations with the highest mean annual maximum temperature (Table A1). If we assume that heat waves reach higher temperatures at locations with a higher maximum temperature, we could hypothesize that there is a higher capacity of $g_{\mathrm{n}}$ to respond to heat waves in genotypes that experience more acute heat waves in their local environment. Of course, more data would be necessary to confirm this hypothesis.

Heat waves in nature often co-occur with water scarcity. Here, we kept any potential effect of soil moisture deficit at a minimum by diurnal irrigation to field capacity. We chose this approach to be able to disentangle heat-wave effects. However, soil water scarcity may exacerbate heat-wave effects and potentially increase differences in the response across genotypes. Further studies on $g_{n}$ should deepen on the role of multiple stressors acting concomitantly to modify the intraspecific responses.

An important open question is how to implement the impact of antecedent conditions into stomatal models. Statistical approaches have been developed to incorporate antecedent effects and to identify the relevant temporal scales [32]. These models rely on continued observations for prolonged periods of time, which is one of the major gaps in nocturnal conductance research, as most observations are available for just one or a few nights. Models incorporating the effect of antecedent conditions are empirical and, consequently, they would need to be coupled with further mechanistic studies that would allow separation of causal from casual correlations. In this experiment, we documented a significant impact of antecedent heat waves on $g_{n}$ and we were able to explain a significant but relatively small portion of the variance. Overall, we propose that long-term monitoring of $g_{\mathrm{n}}$ and detailed mechanistic experiments combined with models for antecedent conditions should be at the forefront of our research efforts. 


\section{Conclusions}

Studies on nocturnal stomatal conductance should routinely assess the role of antecedent environmental conditions, particularly those with extreme climate events such as heat waves. We observed carry-over effects from heat waves on $g_{\mathrm{n}}$ that could be partly explained by changes in $g_{\mathrm{d}}$, but additional studies will be required to more fully elucidate the mechanisms. Genotypic variation in $g_{\mathrm{n}}$ response to heat waves was also observed, suggesting local adaptation and potential importance in climate change scenarios where heat waves become more common.

Author Contributions: Conceptualization, V.R.D., M.E.L. and D.T.T.; Methodology, V.R.D., M.E.L., R.A.S. and D.T.T.; Formal Analysis, V.R.D.; Investigation, V.R.D., M.E.L., R.A.S. and D.T.T.; Writing-Original Draft Preparation, V.R.D., M.E.L., R.A.S. and D.T.T..; Writing-Review \& Editing, V.R.D., M.E.L., R.A.S. and D.T.T.; Funding Acquisition, D.T.T.

Funding: This study was funded by a Science Industry Endowment Fund (project code RP04-122) and supported by the Hawkesbury Institute for the Environment, Western Sydney University. VRD was partly funded from a Ramón y Cajal Fellowship (RYC-2012-10970).

Acknowledgments: The manuscript benefitted from the comments of two anonymous reviewers.

Conflicts of Interest: The authors declare no conflict of interest.

\section{Appendix A}

Table A1. Climate of origin for the different genotypes used in this study. For each location, we provide mean annual precipitation (MAP, mm), mean annual air temperature (MAT, ${ }^{\circ} \mathrm{C}$ ), mean annual maximum air temperature $\left(\mathrm{MXT},{ }^{\circ} \mathrm{C}\right)$, and the mean annual temperature range $\left(\mathrm{ATR},{ }^{\circ} \mathrm{C}\right)$ from meteorological station data for the years 1971-2010.

\begin{tabular}{cccccccc}
\hline Genotype & Location & Latitude & Longitude & $\begin{array}{c}\text { MAP } \\
(\mathbf{m m})\end{array}$ & $\begin{array}{c}\text { MAT } \\
\left({ }^{\circ} \mathbf{C}\right)\end{array}$ & $\begin{array}{c}\text { MXT } \\
\left({ }^{\circ} \mathbf{C}\right)\end{array}$ & $\begin{array}{c}\text { ATR } \\
\left({ }^{\circ} \mathbf{C}\right)\end{array}$ \\
\hline 1 & YASS RIVER & 34.53 & 149.02 & 675 & 14.0 & 28.4 & 25.8 \\
2 & OVENS VALLEY & 36.36 & 146.47 & 653 & 15.0 & 30.5 & 26.8 \\
3 & COONAWARRAW & 37.2 & 140.42 & 646 & 14.5 & 30.0 & 24.0 \\
4 & NYNGAN & 31.33 & 147.11 & 481 & 19.2 & 34.2 & 27.6 \\
5 & CONDOBOLIN & 33.06 & 147.09 & 459 & 17.6 & 33.9 & 28.9 \\
6 & BARMAH SF & 35.5 & 145.07 & 403 & 16.4 & 33.0 & 28.2 \\
\hline
\end{tabular}

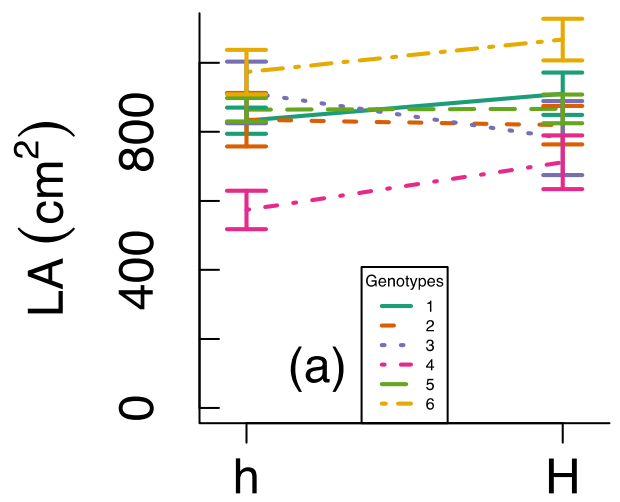

Temperature

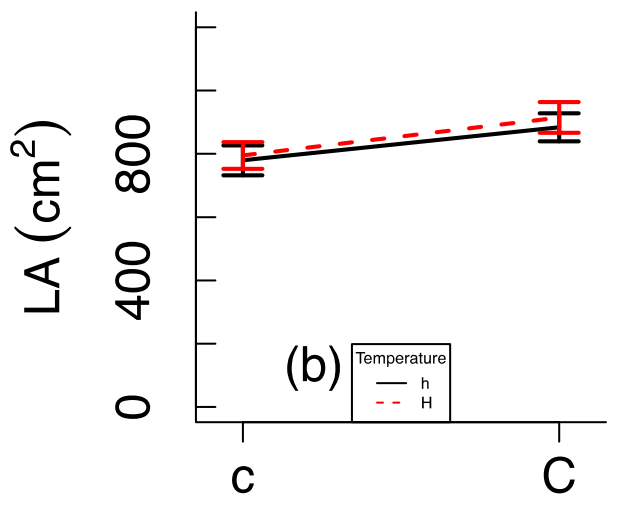

$\mathrm{CO}_{2}$

Figure A1. Variation in leaf area (LA) across genotypes, heat waves, and $\mathrm{CO}_{2}$ concentrations. Data are presented as reaction norms for six genotypes as a function of temperature (a) and as reaction norms for temperature as a function of $\mathrm{CO}_{2}$ treatment $(\mathbf{b})$. Error bars indicate standard errors. 


\section{References}

1. Wang, K.; Dickinson, R.E. A review of global terrestrial evapotranspiration: Observation, modeling, climatology, and climatic variability. Rev. Geophys. 2012, 50, RG2005. [CrossRef]

2. Forster, M.A. How significant is nocturnal sap flow? Tree Physiol. 2014, 34, 757-765. [CrossRef] [PubMed]

3. Lombardozzi, D.L.; Zeppel, M.J.B.; Fisher, R.A.; Tawfik, A. Representing nighttime and minimum conductance in clm4.5: Global hydrology and carbon sensitivity analysis using observational constraints. Geosci. Model Dev. 2017, 10, 321-331. [CrossRef]

4. Cowan, I.R.; Farquhar, G.D. Stomatal function in relation to leaf metabolism and environment. In Integration of Activity in the Higher Plant; Jennings, D.H., Ed.; Cambridge University Press: Cambridge, UK, 1977.

5. Caird, M.A.; Richards, J.H.; Donovan, L.A. Nighttime stomatal conductance and transpiration in C3 and C4 plants. Plant Physiol. 2007, 143, 4-10. [CrossRef] [PubMed]

6. Zeppel, M.J.; Lewis, J.D.; Phillips, N.G.; Tissue, D.T. Consequences of nocturnal water loss: A synthesis of regulating factors and implications for capacitance, embolism and use in models. Tree Physiol. 2014, 34, 1047-1055. [CrossRef] [PubMed]

7. Musselman, R.C.; Minnick, T.J. Nocturnal stomatal conductance and ambient air quality standards for ozone. Atm Env. 2000, 34, 719-733. [CrossRef]

8. Ogle, K.; Lucas, R.W.; Bentley, L.P.; Cable, J.M.; Barron-Gafford, G.A.; Griffith, A.; Ignace, D.; Jenerette, G.D.; Tyler, A.; Huxman, T.E.; et al. Differential daytime and night-time stomatal behavior in plants from North American deserts. New Phytol. 2012, 194, 464-476. [CrossRef] [PubMed]

9. Zeppel, M.J.B.; Lewis, J.D.; Chaszar, B.; Smith, R.A.; Medlyn, B.E.; Huxman, T.E.; Tissue, D.T. Nocturnal stomatal conductance responses to rising $\left[\mathrm{CO}_{2}\right]$, temperature and drought. New Phytol. 2012, 193, 929-938. [CrossRef] [PubMed]

10. Barbour, M.M.; Cernusak, L.A.; Whitehead, D.; Griffin, K.; Turnbull, M.; Tissue, D.T.; Farquhar, G.D. Nocturnal stomatal conductance and implications for modelling $\delta^{18} \mathrm{O}$ of leaf-respired $\mathrm{CO}_{2}$ in temperate tree species. Funct. Plant Biol. 2005, 32, 1107-1121. [CrossRef]

11. Resco de Dios, V.; Diaz-Sierra, R.; Goulden, M.L.; Barton, C.V.; Boer, M.M.; Gessler, A.; Ferrio, J.P.; Pfautsch, S.; Tissue, D.T. Woody clockworks: Circadian regulation of night-time water use in eucalyptus globulus. New Phytol. 2013, 200, 743-752. [CrossRef] [PubMed]

12. Easlon, H.M.; Richards, J.H. Photosynthesis affects following night leaf conductance in vicia faba. Plant Cell Environ. 2009, 32, 58-63. [CrossRef] [PubMed]

13. Resco de Dios, V.; Roy, J.; Ferrio, J.P.; Alday, J.G.; Landais, D.; Milcu, A.; Gessler, A. Processes driving nocturnal transpiration and implications for estimating land evapotranspiration. Sci. Rep. 2015, 5, 10975. [CrossRef] [PubMed]

14. Duarte, A.G.; Katata, G.; Hoshika, Y.; Hossain, M.; Kreuzwieser, J.; Arneth, A.; Ruehr, N.K. Immediate and potential long-term effects of consecutive heat waves on the photosynthetic performance and water balance in douglas-fir. J. Plant Physiol. 2016, 205, 57-66. [CrossRef] [PubMed]

15. Barbour, M.M.; Buckley, T.N. The stomatal response to evaporative demand persists at night in ricinus communis plants with high nocturnal conductance. Plant Cell Environ. 2007, 30, 711-721. [CrossRef] [PubMed]

16. Field, C.B.; Barros, V.; Stocker, T.F.; Dahe, Q.; Dokken, D.J.; Ebi, K.L.; Mastrandrea, M.D.; Mach, K.J.; Plattner, G.-K.; Allen, S.K.; et al. Managing the Risks of Extreme Events and Disasters to Advance Climate Change Adaptation-Special Report of the Intergovernmental Panel on Climate Change; Cambridge University Press: Cambridge, UK, 2012; p. 582.

17. De Dios, V.R.; Loik, M.E.; Smith, R.A.; Aspinwall, M.J.; Tissue, D.T. Genetic variation in circadian regulation of nocturnal stomatal conductance enhances plant fitness. Plant Cell Environ. 2016, 39, 3-11. [CrossRef] [PubMed]

18. Milcu, A.; Puga-Freitas, R.; Ellison, A.M.; Blouin, M.; Scheu, S.; Freschet, G.T.; Rose, L.; Barot, S.; Cesarz, S.; Eisenhauer, N.; et al. Genotypic variability enhances the reproducibility of an ecological study. Nat. Ecol. Evol. 2018, 2, 279-287. [CrossRef] [PubMed]

19. Jones, H. Plants and Microclimate: A Quantitative Approach to Environmental Plant Physiology, 3rd ed.; Cambridge University Press: Cambridge, UK, 2014; p. 423. 
20. Loik, M.E.; Resco de Dios, V.; Smith, R.; Tissue, D.T. Relationships between climate of origin and photosynthetic responses to an episodic heat wave depend on growth $\mathrm{CO}_{2}$ concentration for eucalyptus camaldulensis var. Camaldulensis. Funct. Plant Biol. 2017, 44, 1053-1066. [CrossRef]

21. De Pury, D.G.G.; Farquhar, G.D. Simple scaling of photosynthesis from leaves to canopies without the errors of big-leaf models. Plant Cell Environ. 1997, 20, 537-557. [CrossRef]

22. Bates, D.; Maechler, M.; Bolker, B.; Walker, S. Lme4: Linear mixed-effects models using eigen and s4. R package version 1.1-7. 2014. Available online: Http://cran.R-project.Org/package=lme4 (accessed on 20 February 2018).

23. Buckley, T.N. Modeling stomatal conductance. Plant Physiol. 2017, 174, 572-582. [CrossRef] [PubMed]

24. De Dios, V.R.; Gessler, A.; Ferrio, J.P.; Alday, J.G.; Bahn, M.; del Castillo, J.; Devidal, S.; García-Muñoz, S.; Kaylerd, Z.; Landais, D.; et al. Circadian rhythms have significant effects on leaf-to-canopy gas exchange under field conditions. GigaScience 2016, 5, 43. [CrossRef] [PubMed]

25. Pfautsch, S.; Adams, M.A. Water flux of eucalyptus regnans: Defying summer drought and a record heat wave in 2009. Oecologia 2013, 172, 317-326. [CrossRef] [PubMed]

26. Kupper, P.; Ivanova, H.; Sõber, A.; Rohula-Okunev, G.; Sellin, A. Night and daytime water relations in five fast-growing tree species: Effects of environmental and endogenous variables. Ecohydrology 2017, e1927. [CrossRef]

27. Blackman, C.J.; Aspinwall, M.J.; Resco de Dios, V.; Smith, R.; Tissue, D.T. Leaf photosynthetic, economics and hydraulic traits are decoupled among genotypes of a widespread species of eucalypt grown under ambient and elevated $\mathrm{CO}_{2}$. Funct. Ecol. 2016, 30, 1491-1500. [CrossRef]

28. Phillips, N.G.; Lewis, J.D.; Logan, B.A.; Tissue, D.T. Inter- and intra-specific variation in nocturnal water transport in eucalyptus. Tree Physiol. 2010, 30, 586-596. [CrossRef] [PubMed]

29. Bucci, S.J.; Scholz, F.G.; Goldstein, G.; Meinzer, F.C.; Hinojosa, J.A.; Hoffmann, W.A.; Franco, A.C. Processes preventing nocturnal equilibration between leaf and soil water potential in tropical savanna woody species. Tree Physiol. 2004, 24, 1119-1127. [CrossRef] [PubMed]

30. Schoppach, R.; Claverie, E.; Sadok, W. Genotype-dependent influence of night-time vapour pressure deficit on night-time transpiration and daytime gas exchange in wheat. Funct. Plant Biol. 2014, 41, 963-971. [CrossRef]

31. Christman, M.A.; Richards, J.H.; McKay, J.K.; Stahl, E.A.; Juenger, T.E.; Donovan, L.A. Genetic variation in arabidopsis thaliana for night-time leaf conductance. Plant Cell Environ. 2008, 31, 1170-1178. [CrossRef] [PubMed]

32. Ogle, K.; Barber, J.J.; Barron-Gafford, G.A.; Bentley, L.P.; Young, J.M.; Huxman, T.E.; Loik, M.E.; Tissue, D.T. Quantifying ecological memory in plant and ecosystem processes. Ecol. Lett. 2015, 18, 221-235. [CrossRef] [PubMed]

(c) 2018 by the authors. Licensee MDPI, Basel, Switzerland. This article is an open access article distributed under the terms and conditions of the Creative Commons Attribution (CC BY) license (http://creativecommons.org/licenses/by/4.0/). 